UDK: 821.134.2-055.2"18"

DOI: https://doi.org/10.18485/legado_hispanico.2020.ch4

\author{
Snežana Jovanović ${ }^{1}$ \\ Universidad de Kragujevac \\ Serbia
}

\title{
LA IDENTIDAD DE LA MUJER, DERECHO A LA EDUCACIÓN Y EL IMPULSO DE REDEFINICIÓN DE SU ROL EN LA SOCIEDAD EN LAS MUJERES ESPAÑOLAS, AMERICANAS Y LUSITANAS PINTADAS POR SÍ MISMAS
}

\section{Resumen}

Este trabajo se centra en los textos reunidos en la última colección costumbrista publicada en el siglo XIX - Las mujeres españolas, americanas y lusitanas pintadas por sí mismas-, dirigida por Faustina Sáez de Melgar, la obra dedicada a las mujeres y, como indica su título, íntegramente escrita por mujeres. Releyendo los artículos que forman parte de este libro, pretendemos rastrear las primeras voces reivindicativas sobre el papel de la mujer en la sociedad y abordar las consideraciones de las autoras de la colección en torno a la figura de la mujer y su valía. A la vez nos centramos en sus posturas respecto al tema de la educación como medio de su liberación de la marginación social que padece.

Palabras clave: artículos de costumbre, literatura española del siglo XIX, sociedad, identidad de la mujer, educación femenina.

\footnotetext{
1 jovanovic.nena@gmail.com
} 
La educación es lo principal, y precisamente de ella debe de nacer toda la verdadera fuerza de nuestros derechos, toda la gran influencia que la mujer está llamada a ejercer en el mundo moderno.

(Sáez de Melgar 1881: 12)

\section{Preliminares}

A lo largo de la segunda mitad del siglo XIX en España fueron conseguidos varios logros respecto a la posición de la mujer, con los que se pretendían garantizar ciertos derechos, sobre todo el derecho a la instrucción y la enseñanza: la ley reguladora de la enseñanza popularmente conocida como la ley Moyano (1857), la fundación de la Asociación para la enseñanza de la mujer (1870) o de la Institución de Libre Enseñanza (1876). Sin embargo, como es bien sabido, en la práctica cotidiana estos adelantos legislativos o institucionales a las mujeres han traído poca o ninguna mejora; las leyes no tenían el poder de romper con los prejuicios y las tradicionales ideas profundamente arraigadas en la conciencia colectiva sobre la subordinación de la mujer al hombre, su confinamiento en la esfera doméstica y reducción al papel de buena madre y esposa. Cualquier intento de la mujer de hacerse más visible fue considerado una transgresión y llevaba a la censura y estigmatización. Las propias mujeres difícilmente se liberaban del bagaje de la moral tradicional, de los valores y de la inferioridad que se les inculcaban. De ahí que en los discursos sobre la mujer de las escritoras de la época a menudo se reflejan las posturas ambiguas en cuanto a la identidad y el papel social de la mujer. Ni siquiera la pionera del feminismo en España, la gran Concepción Arenal, consigue desvincularse enteramente de esas ideas. ${ }^{2}$ No obstante, eso no le impide lanzarse en La mujer del porvenir (1869) a la ardua empresa de disipar las ideas falsas y prejuicios sobre la mujer gobernantes en la mayor parte de la sociedad del momento y defender su capacidad intelectual y derecho a la educación lo que le permitiría acceso a todas las profesiones bajo las mismas condiciones que tenían los hombres (Beljić 2019: 97).

Parece que la breve obra de Concepción Arenal, considerada uno de los primeros manifiestos feministas, en el momento en que salió a la luz no tuvo el impacto y la influencia que adquiriría en la posterioridad, ya que tenían que pasar trece años para que apareciera la primera obra dedicada a la mujer Las mujeres españolas, americanas y lusitanas pintadas por sí

\footnotetext{
${ }^{2}$ Varios años más tarde, en La mujer de su casa (1883), Concepción Arenal desmiente las posturas expuestas en La mujer del porvenir declarando que el ángel del hogar no puede ser la mujer del porvenir (Blanco 1998: 459)
} 
mismas. Esta colección redactada por las más notables escritoras de la época, es la última publicada de la serie de colecciones de corte parecido, sin embargo la primera en la que aparece un elemento nada común para la época -la reivindicación de la mujer y de su papel en la sociedad española finisecular-.

\section{Las mujeres españolas, americanas y lusitanas pintadas por sí mismas ${ }^{3}$}

De acuerdo con la norma imperante en la época, la colección publicada en $1881^{4}$ lleva un largo subtítulo bien explicativo, que no deja lugar a dudas en cuanto a su objetivo e intencionalidad: Estudio completo de la mujer en todas las esferas sociales, sus costumbres, su educación, su carácter, influencia que en ella ejercen las condiciones locales y el espíritu general del país a que pertenece. Obra dedicada a la mujer por la mujer y redacta por las más notables escritoras hispano-americanas-lusitanas. En líneas generales, esta obra representa la prolongación de la larga tradición del costumbrismo, corriente literaria inaugurada en la década de los cuarenta por Los españoles pintados por sí mismos (1843-1844) y obedece el patrón de estas publicaciones y sus famosos y muy populares tipos y cuadros de costumbres. A diferencia de otras colecciones parecidas, ${ }^{5}$ Faustina Sáez de Melgar edita su proyecto ambicioso con el

\footnotetext{
${ }^{3}$ En los estudios de algunos autores esta colección aparece bajo el título Las mujeres españolas, americanas y portuguesas pintadas por sí mismas, probablemente por analogía con la colección Las mujeres españolas, americanas y portuguesas: tales como son en el hogar doméstico, en el campo, en las ciudades, en el templo, en los espectáculos, en el taller y en los salones (3 vols.: 1872, 1873, 1876) publicada bajo la dirección de Miguel Guijarro.

${ }^{4}$ Dado que en la portada del libro no figura el año de su publicación, algunos autores afirman que fue publicada en 1882. Díaz Lage (2006: 355) apoya esta postura basándose en las fechas apuntadas en las ilustraciones que acompañan algunos artículos: «(...) si la portada y las primeras ilustraciones están firmadas por Eusebio Planas en 1881, a partir de la lámina que acompaña a La solterona, de María del Pilar Contreras y Alba (pp. 360375), casi todas llevan fecha de 1882».

${ }^{5}$ A raíz del gran éxito de la colección Los españoles pintados por sí mismo, entre 1870 y 1885 en España se publicó una serie de obras que seguían el mismo modelo. Entre las más famosas figuran los siguientes títulos: Las españolas pintadas por los españoles (18711872), Los españoles de ogaño (1872), ya mencionada Las mujeres españolas, americanas y portuguesas, Madrid por dentro y fuera (1873), Los hombres españoles, americanos y portugueses (1881). La gran difusión de Los españoles pintados por sí mismos traspasa las fronteras de España lo que prueban las colecciones publicadas en Hispanoamérica: Los Cubanos pintados por sí mismos (La Habana, 1852) o Los mejicanos pintados por sí mismos (México, 1854), por mencionar algunas.
} 
que incursiona en el género que tradicionalmente favorecía la autoría masculina, reuniendo un amplio grupo de escritoras que ofrecen un variado panorama de tipos de la mujer hispana. Entre las autoras de estos textos figuran Emilia Pardo Bazán, Rosario de Acuña, Blanca de los Ríos, Ángela Grassi, Julia de Asensi, Patrocinio de Biedma, Joaquina de Balsameda o Concepción Gimeno. Dada la marginalización de las mujeres y aún más de las que pretendían dedicarse a la literatura, la abundancia de los nombres que aparecen en la colección podría resultar sorprendente. Hoy en día la mayoría de ellas es poco conocida y olvidada por el canon de literatura porque su actividad literaria se limitaba a escribir para la prensa periódica. Como apunta Hibbs Lissorgues (2008: 326), se dedicaban a los "géneros tolerados y considerados bastante inocuos: crónicas de moda, manuales escolares, guías epistolares, por ejemplo». Desde esta óptica podríamos meditar sobre el contenido del prólogo de la editora que abre la obra en el que se dirige más que al público, a sus colegas escritores, justificando la finalidad de su empresa:

No es una obra de combate, no es un libro de polémica el que tratamos de escribir; únicamente y como su título indica, vamos a dedicar un número más o menos crecido de páginas a presentar a la mujer tal como es, lo mismo en España que en Portugal, nuestra hermana, que en América y en Filipinas nuestras hijas (1881: 1$)^{6}$

Parece como si la editora con estas palabras quisiera mitigar los efectos que podrían causar las verdaderas aspiraciones que expresa tanto ella como una buena parte de sus colaboradoras, el deseo de «constituirse en juez y guía de su propio sexo», «conseguir una auténtica y cumplida formación profesional e intelectual para la mujer» y además expresar «las preocupaciones, inquietudes e ideales de un cierto sector de la población femenina» (Ayala Aracil 1993: 201-202), para lo que el artículo de costumbres se presta como una forma idónea por ser un género ameno y a la vez instructivo.

La mayor parte de los 64 artículos $^{7}$ que forman esta obra fueron escritos a solicitud de la editora para la ocasión, sin embargo, el artículo La cigarrera $^{8}$ de Emilia Pardo Bazán fue creado varios años antes y aquí

\footnotetext{
${ }^{6}$ Citado por Ayala Aracil (1993: 196).

${ }^{7}$ Curiosamente, en la colección está incluida la breve biografía de solo una de su colaboradoras, Julia de Asensi, que participa con tres artículos (La aristócrata devota, La trapera y La pupilera), elaborada por Matilde Gómez.

${ }^{8}$ Sobre el tema consultar Díaz Lage: 2006.
} 
aparece en una versión revisada y modificada. Algunas autoras participan con más de un texto, como Julia de Asensi (3), Concepción Gimeno (2) o Patrocinio de Biedma (4). De acuerdo con el propósito de la editora de mostrar la imagen completa y verídica de la mujer para combatir «ciertos veredictos injustos» $\mathrm{y}$ «tendencias engendradas por las ideas extraviadas» (1882: 8), en la colección están recogidos los artículos que muestran la imagen de la mujer de diferentes estratos sociales y profesiones, pero también están incluidos los tipos más representativos de la geografía española. A pesar del título de la obra que demuestra la pretensión de la editora de no limitarse exclusivamente a los tipos españoles e incorporar algunos de otros países, la mujer lusitana está representada por solo dos artículos La fidalga portuguesa (Concepción Gimeno de Flaquer) y La mujer portuguesa (Natividad de Rojas y Ortiz de Zárate), mientras que del mundo hispanoamericano aparece retratada nada más la mujer de Cuba y de México: La mujer de La Habana (Olimpia Alborad), La mujer mexicana (Refugio Barragán de Toscano,) y de la misma autora Una boda de Tuxpan.

\section{Esencia femenina y educación moral}

Uno de los rasgos característicos del conjunto de los textos de esta colección es la constante preocupación por la moralidad, virtud y deber de la mujer que no es otra cosa que el claro reflejo del concepto predominante de la mujer como centro moral de la sociedad de la época. Patrocinio de Biedma en su artículo La madrileña resume las virtudes más puras que debe poseer una mujer y las que no debe sacrificar bajo ningún pretexto: «abnegación de la madre, el cariño de la esposa, la lealtad de la amiga y los frutos de trabajo» (1881: 164). Para algunas autoras la fe y el sentimiento religioso son inseparables de la virtud. Así para Antonia Díaz de Lamarque en la doctrina evangélica y la religión católica está el origen de toda virtud; el sentimiento religioso ayuda a la mujer a dominar sus pasiones. Su opinión comparte Josefa Estévez de García del Canto, afirmando que una mujer religiosa es «el escudo contra el mal». Para Blanca de los Ríos sin religión la mujer se quedaría nada más con el instinto y la ignorancia. Describiendo a las andaluzas en el artículo La hija del pueblo expone su definición de la mujer en la que resuena la vieja idea de la débil naturaleza de la mujer necesitada de la protección y amparo masculino, de la mujer como un ser que carece de las capacidades racionales del hombre porque ella es toda afecto. De ahí que «si el hombre se desmoraliza la mujer se prostituye: el hombre mezcla a sus pasiones un rayo de reflexión, la mujer confunde con ellas torrentes de fantasía» (1881: 115). 
La maternidad es la más sublime manifestación de la mujer y el matrimonio la base de la historia y la sociedad. María del Pilar Contreras y Alba expresa una postura poco convencional respecto al matrimonio, aunque no niega su importancia; no acepta los matrimonios de conveniencia contraídos únicamente por cumplir un deber de la sociedad, alegando que podrían tener las consecuencias funestas y defiende el derecho de las mujeres a no casarse:

Y si en efecto, el matrimonio es una de las más altas perfecciones humanas,
pues con él se eleva la mujer a la categoría de madre, ¿por qué de santo
consorcio se ha de hacer un negocio mezquino, un medio de lucro,
bastardeando los nobles y elevados sentimientos de la mujer? ¿Por qué
se la ha de martirizar hasta el doloroso extremo de hacerla colocar por su
propia mano la primera piedra del edificio de la desventura, aceptando
el matrimonio de conveniencia, jurando eterna fe al pie de los altares, al
hombre que no ama, que no le es dado amar? ¿Acaso es merecedora a que
se le exijan tan grandes sacrificios? (1881: 363)

Ana María Sólo de Zaldívar comparte su rechazo de los matrimonios sin un vínculo sentimental que habitualmente conciertan los padres de las mujeres jóvenes eligiendo al futuro marido de sus hijas a su agrado, a alguien que reúne ciertas calidades, sobre todo económicas, sin consultarlas. Para ella, estas uniones son la "prostitución del alma», impiden a la mujer ser la compañera del hombre y la convierten en su socia en los cálculos matemáticos. La escritora admite que la mujer no está en el mundo para dominar, sino para amar; es un ser débil, pero solo en el sentido físico, de ninguna manera inferior intelectualmente al hombre.

Cándida Sanz y Cressini no cuestiona que la esencia de la mujer sea grande y sublime, es más, considera que el mayor valor de la mujer reside en su bondad, sentimiento, amor, virtud e inteligencia y que esos rasgos son los requisitos imprescindibles para que la mujer pueda ocupar en la sociedad lugar que no sea el ínfimo que habitualmente se le destina. Tampoco cuestiona sus funciones fundamentales de la hija solícita, la madre amorosísima y la esposa fiel. No obstante, a las prendas de su naturaleza y moral suma otro factor que podríamos considerar como el eje central de la mayoría de los artículos de la colección y del que hablaremos con más detenimiento en el siguiente bloque - la educación. En su parecer la educación es el medio de liberación dado que la mujer ignorante únicamente puede ser una esclava: «La mujer que a más de estas bellas condiciones, reúna la instrucción, la sencillez, la previsión y la 
actividad, esta es la mujer perfecta que traza la moral espiritista, porque esta es su verdadera misión: esta es la mujer de la mañana» (1881: 222).

\section{La instrucción de la mujer y su misión en la sociedad moderna}

Ninguna de las autoras niega la importancia de la educación moral, pero sí se oponen a la idea de que esta sea suficiente para la mujer y la única a la que tiene derecho y acceso. En diferente medida todas están conscientes de las exigencias y retos que consigo traen los nuevos tiempos y desde distintas perspectivas plantean la cuestión de la instrucción de la mujer en sus textos. Patrocinio de Biedma, la escritora con más presencia en esta obra colectiva, aboga por una mejor y más extensa educación para la mujer determinándola como vía para reducir la posición de desigualdad en la que se encuentra respecto al hombre. Da cuenta de algunos avances significativos que se han producido, que el Consejo superior de instrucción pública ha reconocido la necesidad de apertura de centros educativos donde las mujeres obtendrían una instrucción más completa que la insuficiente que solía tener y permitió su acceso a ciertas carreras profesionales, "prefiriendo las de comercio y telégrafo» (1881: 168). Desde la posición muy cercana a la de los krausistas resalta que únicamente a través de la cultura y educación es posible dignificar el papel de la mujer y conseguir la regeneración de la sociedad: «España volverá a ser grande, fuerte y respetada, y a la mujer deberá en gran parte su prosperidad y regeneración» (1881: 25). Para hacer posible que la mujer ocupe ese papel es necesario que antes entienda su «misión» en la sociedad moderna, sin embargo, varios factores obstaculizan esta tarea. Entre otros, determinadas conveniencias sociales que fomentan el desarrollo de ciertos rasgos negativos de la mujer. La autora se refiere ante todo a lo que señala como una «aberración histórica» - la vida del eterno tiempo libre que se impone a la mujer burguesa, una vida que paradójicamente la aleja de sus deberes: del matrimonio, maternidad y domesticidad y la lleva a la frivolidad, ociosidad e ignorancia. La escritora jiennense propone que las mujeres de las clases adineradas, sobre todo las madrileñas, puesto que poseen posición y mayor grado de independencia, utilicen su tiempo libre de manera útil difundiendo la educación entre los sectores menos afortunados y las mujeres del pueblo que tradicionalmente están siempre en la situación más precaria que las de las ciudades viviendo en la «dolorosa esclavitud de la ignorancia» (1881: 412). Destaca como emblemático el caso de la escasa educación de las mujeres de Jaén que se guían en la vida únicamente por sus instintos 
y costumbres; pasan su existencia aisladas, inconscientes de la propia ignorancia, carentes de ocasión y de voluntad de aprendizaje. En su modo de ver lo último representa el mayor impedimento para conseguir cualquier mejora, ya que la mujer misma tiene que iniciar esos cambios:

Si la mujer quiere ${ }^{9}$ ilustrarse vencerá lo que imposible parece: si no hace suyo el empeño, triste es decirlo, pero será cada vez más visible su atraso en la marcha general de los pueblos civilizados, y olvidada, ignorada, lejos de ocupar el lugar a que tiene derecho por sus virtudes, quedará relegada a no salir de su pobre rincón natal, pues lejos de su pueblo, y en comparación con las ilustradas mujeres del día, hará una triste figura, a pesar de su valor moral, pues la sociedad solo está obligada a juzgar por lo que ve, y en ella encuentra la nulidad insoportable de la mujer-máquina de los tiempos de Mari-Castaño, anacronismo vivo en el cuadro de la civilización (1881: 412-413).

El mensaje que dirige a las mujeres es: «Haceos ilustradas para ser perfectas» (1881: 404) y el modelo a seguir que propone es la mujer inglesa, bella y útil a la vez, que gracias a sus esfuerzos ha conseguido el derecho a trabajar y educarse, y ha sabido utilizar hábilmente los conocimientos obtenidos no solo en la vida profesional sino también en la vida doméstica aumentando de este modo el bienestar familiar. En ese sentido propugna que la educación de las mujeres en España sea obligatoria. Por otro lado, la escritora tiene un mensaje para los hombres: «No teman los moralistas que la familia falsee sus bases si se arranca a la mujer de la ignorancia: la ilustración no será jamás un elemento de muerte porque es, al contrario, un elemento de vida» (1881: 820).

Ana María Sólo de Zaldívar, la autora que aparte de unas incursiones ocasionales en la poesía al estilo becqueriano entregó su vida a la pedagogía, en esta colección se presenta con una semblanza de La mujer extremeña. Afirmando que en Extremadura no existe un tipo único de la mujer dado que su carácter se modela dependiendo de un conjunto de factores entre los que figuran las costumbres, la educación y la instrucción, Ana María Sólo de Zaldívar examina a las mujeres de estas tierras según el estrato social al que pertenecen. Pese a que llevan vidas dispares, tienen algo en común - la deficiente educación. Los atrasos del sistema educativo existente se evidencian sobre todo en la fase decisiva para el desarrollo afectivo, social e intelectual de una persona, en la escolarización de los niños, que hasta en las niñas aristócratas se reduce a «saber leer, y no muy bien, a escribir muy mal; algo de aritmética, que pronto olvida y un poco de historia sagrada y doctrina cristiana (1881: 478)». Otro problema

\footnotetext{
${ }^{9}$ La cursiva es de Patrocinio de Biedma.
} 
es que las niñas del pueblo no asisten a las clases aunque hay escuelas municipales, por eso la autora, igual que Patrocinio Biedma, aboga por la educación infantil obligatoria ya que la educación de la mujer es «el mayor bien que pueda hacérsela» (1881: 480) y el único medio para que desarrolle su potencial. También comparte su posición sobre la educación como fuerza que podría borrar las diferencias tanto de sexo como de clase: «(...) la educación es la que verdaderamente da el sello de la nobleza a una persona: entre dos de educación análoga, no existe diferencia de clases, profesan las mismas ideas sobre el mundo, tienen los mismos principios, y sus aspiraciones son idénticas» (1881: 478).

Camila Calderón es otra de las colaboradoras que ve la educación como factor de igualdad o dicho de otro modo, lo que separa a los individuos de una sociedad no es la clase a la que pertenecen sino su nivel de educación. Retratando con tintes crítico-satíricos el tipo de la mujer joven de familia de ricos de nuevo cuño censura su noción vulgar de educación. La instrucción en sí para ellos carece de relieve; lo importante no es el aprendizaje sino mantener la imagen de la familia adinerada y elegir el colegio de acuerdo con esa imagen. Al terminar sus estudios la señorita rica sigue igual de ignorante, y dado que su dinero y su belleza no encubren las faltas de su educación, se casa con alguien de escasa instrucción como la suya y de esa manera perpetua el círculo de ignorancia. Este tipo guarda muchas similitudes con la mujer rica de Ventura Hidalgo, la clásica «mujer adorno», «planta de invernadero».

Envarios artículos de esta colección la falta de educación se relaciona con las condiciones duras e injustas en las que las mujeres desempeñan los pocos oficios a los que en esa época pueden optar. Las autoras trazan semblanzas de las actividades a las que se dedican las mujeres de las clases más humildes por necesidad, para poder mantener sus familias. Sus criadas, lavanderas, cigarreras, porteras, lecheras, traperas o costureras aceptan su destino y largas horas de trabajo agotador sin rechistar. Retratando a la sardinera santanderina, Joaquina A. Oliván apunta que la mujer trabajadora de las clases populares, con su nula instrucción, no tiene otra salida. Además, la falta de tiempo y de instrucción trae consigo una consecuencia aún más funesta, la imposibilita a realizar una de sus funciones básicas - educar a sus hijos. La autora claramente achaca a la sociedad la responsabilidad de "proporcionar los medios de instrucción y de dirección que hace grandes a las colectividades, instruidos a los pueblos, y buenos y honrados a los individuos» (1881: 553).

La figura más representativa da la recopilación, Emilia Pardo Bazán, en su texto La cigarrera se adentra en el mundo de la mujer obrera, tema al que volverá algunos años más tarde en la Tribuna (1883), 
considerada la primera novela social y naturalista de España. De manera casi documental Pardo Bazán pinta las condiciones de explotación laboral de las cigarreras que al terminar su jornada laboral se retiran a sus hogares para seguir trabajando. Con cierta simpatía la autora constata que estas «infelices mujeres» se distinguen de las otras representantes de su género. Dado que entran en la fábrica siendo todavía niñas, esta vida y trabajo duro forjan su carácter: «No es la cigarrera la tosca mujer del campo, de sentidos torpes y obtusos, de tarda comprensión, tímida al par que brutal; es al contrario una criatura lista como la pólvora, de afinados nervios y rápidas impresiones» (1881: 798). Son más atrevidas, libres y propensas a protestar. Sin apoyo del gobierno, abandonadas a su destino, se ven obligadas a exigir sus derechos por sus propios medios.

\section{Mujer que sabe latín... no tiene marido ni buen fin}

Si la posición de la mujer carente de educación era difícil, ser mujer instruida en la sociedad española de esos tiempos no presentaba menor reto. Considerada «bicho raro, ser perjudicial y extraño», como lo testimonia Prudencia Zapatero de Angulo (1881: 437), o «ratón de librería, pedagogo con faldas, bachillera necia e insufrible» (1881: 870), a la mujer culta no se reconocía la capacidad de ser buena esposa y madre. En la digresión introductoria de su artículo La marisabidilla, Pilar Pascual de San Juan se detiene a abordar las condiciones en la que está sumida la mujer instruida y asume una actitud crítica frente a la misoginia y desprecio que la rodean. Se rebela contra el tratamiento injusto que recibe ya que a menudo se la iguala con la erudita falsa y presumida que da nombre a dicho artículo, tipo recurrente de la literatura costumbrista. Admite que la mujer demasiado pretenciosa encarnada en este estereotipo es merecedora de reprobación, pero levanta la voz contra la costumbre de tildar a todas las mujeres educadas de pedantes alegando que es un rasgo que se presenta indistintamente en ambos sexos. Pinta a su marisabidilla, Paquita, como una mujer pomposa y superficial que «entiende de todo menos de cumplir con sus deberes» (1881: 827), mujer que es una «verdadera calamidad» para su familia porque no realiza ninguno de los papeles asignados a la mujer. En su pasión por los «estudios» falla como hija, esposa y madre. Parecido a sus colegas masculinos la autora parodia su forma de vida y su concepto equivocado del verdadero significado de los estudios que esta iguala con la lectura sin criterio alguno. Como era habitual, no podía faltar la alusión a las lecturas mal orientadas - novelas históricas y de costumbre, «algunas de dudosa moralidad». 
En lo que Pilar Pascual de San Juan difiere del planteamiento de sus colegas masculinos es en la causa que lleva a esos comportamientos censurables. Ella los ve como consecuencia de mala educación, actitud altanera de los hombres hacia las mujeres y poca estima que les tienen. La escritora rehúye el establecido canon entre los géneros según el que únicamente el hombre es un ser racional, mientras la naturaleza de la mujer es instintiva y afectiva: «Que dejen eso del instinto para su perro, y concediéndonos una razón tan perfecta como la suya, que traten de ilustrarla con una educación sólida, y a la medida que crezca el número de las mujeres estudiosas, irá siendo menor el de las marisabidillas» (1881: 823). Por otro lado, detrás de la oposición de los hombres a la educación de las mujeres está el miedo de que invadan su terreno. El miedo también motiva el rechazo de las mujeres escritoras cuyas obras condenan sin leerlas siquiera. Pilar Pascual de San Juan les lanza una respuesta directa: "Que nos dejen en paz y si no quieren leer nuestros escritos que no los lean. Nosotras no escribimos para los hombres: porque los sabios no necesitan nuestros humildes consejos, ni nada de cuanto pudiéramos decirles, y los ignorantes desdeñan nuestras obras» (1881: 823).

La contribución de Felicia ${ }^{10}$ a esta colección es el artículo titulado La mujer instruida, otro texto en el que se expone la crítica a las mujeres pedantes. Esta vez el tipo se nos presenta a través de la poco frecuente perspectiva masculina. Ricardo es un hombre prejuicioso y no muy amante de la moderna mujer culta, dado que la identifica con las marisabidillas y su erudición fastidiosa. De ahí que se casa con su contrapunto, una mujer bonita pero superficial y frívola, y acaba en un matrimonio desventurado, descubriendo tarde el grave error que había cometido en lo que le ayuda haber conocido en una tertulia una verdadera mujer ilustrada. La autora contrarresta la verdadera y falsa educación en los personajes de Modesta y Beatriz, queriendo desvincularse de la segunda y ensalzar la primera como modelo a seguir.

En el artículo La poetisa del pueblo, María del Pilar Contreras de Alba defiende el derecho de la mujer a dedicarse a los «asuntos de pluma propios de hombres» (1881: 688) y deja constancia de la posición poco envidiable de las mujeres que se atreven a adentrarse en el territorio prohibido. Una mujer con dotes y aspiraciones literarias está en continua lucha contra los intentos de la sociedad de hacerla invisible o desprestigiarla, y los obstáculos a los que se enfrenta aumentan proporcionalmente al tamaño de la población en la que viven. A diferencia de la poetisa de la ciudad, la del pueblo cuenta solo con su talento ya que recibe una educación

${ }^{10}$ Seudónimo de Virginia Felisa Aubert y de Nova. 
bastante limitada, no tiene acceso a las tertulias literarias y las bibliotecas, y sus lecturas se reducen a las «novelas de pasatiempo» o los folletines de periódicos. En esos ambientes reducidos a menudo se la tacha de pedante y marisabidilla por sus inclinaciones literarias, se cuestiona su capacidad de ser buena madre y se convierte en el blanco de la envidia, murmuraciones y ataques. Sin embargo, a la autora le cuesta asumir que sean las propias mujeres las que estigmatizan a las literatas y las atacan despiadadamente en vez de apoyarlas:

\begin{abstract}
Unas, las más eruditas, opinan que no puede ser suyo lo que escribe, en virtud a la escasa educación que ha recibido; y se burlan de sus producciones y se ríen de sus afanes; otras, no pudiendo menos de confesar y conocer el justo mérito de sus poesías y deseando ridiculizar ante el mundo a la que nació superior a ellas, hacen uso de la sátira mordaz: cuentan mil anécdotas referentes a su víctima, atribuyéndola defectos que no tiene, y todo es hijo de vergonzosas pasiones, por vengar quizá los agravios juveniles, sin pensar que solo en corazones bajos y miserables pueden tener cabida tan bastardos sentimientos (1881: 687).
\end{abstract}

Trazando el retrato de La poetisa romántica, Graciella ${ }^{11}$ se sitúa en la misma línea que sus compañeras de pluma criticando los convencionalismos y poco respeto que recibe la mujer escritora tanto de los hombres como de la sociedad en general. La autora sugiere que los hombres se sienten amenazados por la mujer escritora y ahí busca el motivo de sus críticas incesantes, independientemente de la calidad de sus producciones: «los de talento porque prefieren la mujer poco sabia, los necios porque no sufren que la mujer valga más, y ser ante ella segunda figura» (1881: 151). Para Graciella escribir y ser escritor no es lo mismo y pide para las literatas el mismo trato que tienen los hombres - hacer la distinción entre las escritoras y las pedantes que con su comportamiento solo consiguen empañar los logros de las primeras-.

\title{
6. Reflexiones finales a modo de conclusión
}

Está claro que la colección Las mujeres españolas, americanas y lusitanas pintadas por sí mismas nace como reacción a la imagen de la mujer presentada en las compilaciones parecidas que se publicaban desde los mediados del siglo XIX y sus artículos firmados exclusivamente por los autores masculinos. La pretensión similar, la de corregir la imagen distorsionada, en este caso de toda la nación, que poblaba las

\footnotetext{
${ }^{11}$ La identidad de esta autora sigue siendo desconocida.
} 
obras de autores foráneos, igual que la necesidad de dejar constancia de las auténticas costumbres españolas, ha inspirado la creación de las obras que le sirvieron de modelo. Sin embargo, el elemento fundamental que distingue nuestra colección de sus predecesores es el matiz de la reivindicación del rol de la mujer en la sociedad moderna, de su participación en la sociedad, sus derechos y sobre todo derecho a la educación, inusitado en la literatura de corte costumbrista. Las autoras de esta colección en sus textos no proponen una ruptura radical con las expectativas sociales sobre su identidad. Ellas mismas todavía están impregnadas de los valores convencionales consensuados por la sociedad decimonónica. Estos principios ideológicos y morales, por un lado apoyados en los postulados religiosos del cristianismo y por otro en las normas de manuales de etiqueta, fueron encarnados en la esposa virtuosa y ama de casa, pilar de la familia y fuente del abnegado apoyo a su esposo (Karanović 2013: 210). La mujer ideal es casta, modesta, discreta, sabe guardar la compostura. Y es depositaria del honor del marido. De ahí que en varios artículos está patente la finalidad didáctica; a través de la pintura de tipos se exponen ciertos rasgos femeninos merecedores de censura y otros que se ofrecen como modelo a seguir. No obstante, al mismo tiempo, de manera más o menos discreta en sus escritos asoma la idea de que la mujer vale para algo más, que posee las capacidades intelectuales para dedicarse a las actividades fuera de sus labores domésticos sin que esto afecte el ámbito familiar. Las autoras ya no están dispuestas a admitir la vieja creencia sobre la mujer como un ser imperfecto y por naturaleza intelectualmente inferior al hombre. Reclaman mayor acceso de las mujeres a la educación y una educación más completa que no ofrecería solo conocimientos superficiales e inútiles. ¿Cómo una mujer puede cumplir con las expectativas de la sociedad y ser la compañera de hombre si es ignorante? La mujer instruida sería capaz de educar a sus hijos y en el sentido más amplio al pueblo entero, contribuyendo así a la reducción del retraso intelectual en el que estaba sumido el país en la época y a la conversión de los españoles en una nación moderna. Nuestras autoras también se hacen eco de la actitud contradictoria de los hombres que critican severamente a la mujer por ser frívola y superficial, a la vez que impiden sus intentos de educarse y su deseo de desarrollar sus capacidades interpretan como una amenaza. En este sentido el mayor logro que evidencian los textos de esta compilación es que las mujeres, por lo menos las instruidas, han tomado la conciencia de su situación y asumido que son ellas mismas las que tienen que iniciar los cambios. 


\section{REFERENCIAS BIBLIOGRÁFICAS}

Arce Pinedo 2007: Rebeca Arce Pinedo. Dios, patriay hogar. La construcción social de la mujer española por el catolicismo y las derechas en el primer tercio del siglo XX. Santander: Publican, Ediciones de la Universidad de Cantabria.

Arenal 2010: Concepción Arenal. La mujer de porvenir. Alicante: Biblioteca Virtual Miguel de Cervantes. Web. 14/10/2019.

Ayala Aracil 1993: Ma de los Ángeles Ayala Aracil. Las colecciones costumbristas (1870-1885). Alicante: Universidad de Alicante.

Ayala Aracil 1995: Ma de los Ángeles Ayala Aracil. «Costumbrismo y reivindicación feminista». España contemporánea: Revista de literatura y cultura, 2: 11-20. Web. 15/12/2019.

Ballarín Domingo 1989: Pilar Ballarín Domingo. «La educación de la mujer española en el siglo XIX». Historia de la educación. Revista interuniversitaria, 8, Universidad de Salamanca: 209-215.

Beljić 2019: Izabela Beljić. „Žena budućnosti: španski feministički manifest". Konsepsjon Arenal. Žena budućnosti. Prevela sa španskog i pogovor napisala Izabela Beljić, Beograd: Partenon, Bibliotheca Hispania, 91-119.

Blanco 1998: Alda Blanco. «Teóricas de la conciencia feminista». Alda Blanco et al. La mujer en los discursos de género. Textos y contextos en el siglo XIX. Barcelona: Icaria editorial, 445-473.

Díaz Lage 2006: Santiago Díaz Lage. «Dos versiones de La cigarrera, texto olvidado de Emilia Pardo Bazán». La Tribuna: cuadernos de estudios da Casa Museo Emilia Pardo Bazán, 4: 355-384. Web. 15/12/2019.

Gómez-Ferrer Morant 2002: Guadalupe Gómez-Ferrer Morant. Hombres y mujeres. El difícil camino hacia la igualdad. Madrid: Editorial Complutense.

Hibbs Lissorgues 2008: Solange Hibbs Lissorgues. «Escritoras españolas entre el deber y el deseo: Faustina Sáez de Melgar (1834-1895), Pilar Sinués de Marco (1835-1893) y Antonia Rodríguez de Ureta». Pura Fernández \& Marie-Linda Ortega (eds.), La mujer de letras o letraherida. Discursos y representaciones sobre la mujer escritora en el siglo XIX. Madrid: Consejo Superior de Investigaciones Científicas, 325-343.

Karanović 2013: Владимир Карановић. Идеологија либерализма и традиционализам у роману Регенткиња Леополда Аласа Кларина. Београд: Филолошки факултет Универзитета у Београду. 
Karanović 2016: Владимир Карановић. „Емилија Пардо Басан и феминистичка мисао: право на личну слободу и концепција «нове жене» у роману Успомене једног нежење“, Радови Филозофског факултета у Источном Сарајеву (Филолошке науке), 18: 109-126.

Mujeres españolas, americanas y lusitanas pintadas por sí mismas, Las. Estudio completo de la mujer en todas las esferas sociales, sus costumbres, su educación, su carácter, influencia que en ella ejercen las condiciones locales y el espíritu general del país a que pertenece. Obra dedicada a la mujer por la mujer y redacta por las más notables escritoras hispano-americanas-lusitanas bajo la dirección de la señora Faustina Sáez de Melgar, e ilustrada con multitud de magníficas láminas dibujadas por don Eusebio Planas. Barcelona: Establecimiento tipográfico - Editorial de Juan Pons, 1881. Web. 10/10/2019.

Peñas Ruiz 2014: Ana Peñas Ruiz. El artículo de costumbres en España (1830-1850). Vigo: Editorial Academia de Hispanismo.

\section{THE FEMALE IDENTITY, THE RIGHT TO EDUCATION AND THE IMPULSE TO REDEFINE THEIR ROLE IN SOCIETY IN LAS MUJERES ESPAÑOLAS, AMERICANAS Y LUSITANAS PINTADAS POR SÍ MISMAS}

\section{Summary}

This paper focuses on the texts gathered in the last costumbristic collection published in the 19th century -Las mujeres españolas, americanas $y$ lusitanas pintadas por sí mismas, directed by Faustina Sáez de Melgar, dedicated to women and as its title indicates, written entirely by women. Rereading the articles contained in this one volume compendium, we intend to trace the first vindictive voices about the role of women in society and address the concept that the authors of the collection had of women and their own worth. At the same time we centre on their positions on the issue of education as a means by which women can free themselves from the social marginalization they suffer.

Keywords: costumbristic articles, XIX century Spanish literature, society, women's identity, women's education. 